Nova Southeastern University

Florida

NSUWorks

Faculty Articles

Ron and Kathy Assaf College of Nursing

9-2017

\title{
Strategies to Promote Health in North American French Jewish Immigrants
}

\author{
Balkys L. Bivins \\ Nova Southeastern University, bbivins@nova.edu \\ Rosemary F. Hall \\ University of Miami
}

Follow this and additional works at: https://nsuworks.nova.edu/hpd_con_facarticles

Part of the Nursing Commons

\section{NSUWorks Citation}

Bivins, Balkys L. and Hall, Rosemary F., "Strategies to Promote Health in North American French Jewish Immigrants" (2017). Faculty Articles. 247.

https://nsuworks.nova.edu/hpd_con_facarticles/247

This Article is brought to you for free and open access by the Ron and Kathy Assaf College of Nursing at NSUWorks. It has been accepted for inclusion in Faculty Articles by an authorized administrator of NSUWorks. For more information, please contact nsuworks@nova.edu. 


\begin{tabular}{|l|c|c|}
\hline $\begin{array}{c}\text { INNOVATIVE } \\
\text { JOURNAL }\end{array}$ & $\begin{array}{c}\text { Contents lists available at } \underline{w w w . i n n o v a t i v e j o u r n a l . i n} \\
\text { INTERNATIONAL JOURNAL OF NURSING DIDACTICS } \\
\text { homepage: } \underline{\text { http://innovativejournal.in/ijnd/index.php/ijnd }}\end{array}$
\end{tabular}

\title{
Strategies to Promote Health in North American French Jewish Immigrants
}

\author{
${ }^{1}$ Balkys L. Bivins, MSN, ARNP, BSN, ${ }^{2}$ Rosemary F. Hall PhD, RN, MSN, BSN \\ ${ }^{1} \mathrm{PhD}$ student, Barry University, Miami Shores, Florida 33161 \\ Adjunct Professor at Nova Southeastern University, Palm Beach Gardens, Florida 33410 \\ ${ }^{2}$ Retired professor from the University of Miami, Coral Gables, Florida
}

DOI: http://dx.doi.org/10.15520/injd.2017.vol7.iss9.245.

\begin{abstract}
Anti-Semitism in the form of violent acts is on the rise in France and throughout Europe. These incidents and the looming threat of targeted violence are leading to the outmigration of Jewish individuals in France to Israel, Canada, and the United States. The health impact of this migration on individuals of the French Jewry who are now residing in the United States has not been studied. This paper will propose and address the need for culturally tailored nursing strategies to make a positive impact on the health, well-being, and lives of these individuals. Additionally, the writers will discuss the challenges faced by these new immigrants, how acculturation may be impacted by economic status, and how specifically focused nursing care can impact the physical, psychological, spiritual, and social well-being of these individuals in their new home (or host country).
\end{abstract}

Keywords: Individuals of French Jewry, culturally tailored nursing strategies, health and well-being

\section{INTRODUCTION AND PURPOSE}

This paper will address salient approaches and concrete strategies for promoting health to the individuals of the French Jewry who have migrated to the United States (within the last 10 years) by exploring the role of nursing in assessing the relevant needs of this population. As defined by the World Health Organization (WHO) in 1946, optimal health is more than the absence of illness; it encompasses the overall physical, social, and mental well-being of an individual (WHO, 2017). In a further elaboration in 1948, the WHO included health and wellness as fundamental rights in its Universal Declaration of Human Rights (WHO, 2017). Accordingly, effective approaches to fulfilling the obligation to migrants must include concrete strategies to address the health and health care needs of these individuals. In addition, the American Nurses Association (ANA) Nursing's Social Policy Statement further mandates that nursing as a profession has a duty to utilize evidence-based practice addressing the health needs of all individuals (ANA, 2010).

As the United States continues to reflect its history as a nation of immigrants, nurses must develop culturally tailored nursing care that is responsive to the varied health status of those immigrants. Although the research on immigrant health is sparse and inconclusive, the writers will address the general decrease in attention and access to care, the impact on the physical and psychological well-being of immigrants, and the concept of acculturation and its effect on migration of the individuals of the French Jewry. According to Berry (1997), the degree of acculturation plays a major role on an individual's overall health. The writers will discuss acculturation, challenges faced by immigrants, and the part that nursing must play to impact the immigrant's physical, psychological, social, spiritual, and economic well-being.

\section{HISTORICAL BACKGROUND}

The most pernicious phase of anti-Semitism in the modern era began when Adolf Hitler's Nazi party took power in Germany and implemented state-sanctioned persecution of Jews in 1933, leading to what would become World War II and the Holocaust (Welch, 2014). According to Benbassa (1999) in The Jews of France: A History from Antiquity to the Present, however, there are longstanding tensions between the Jewish and Muslim people that persist today in Europe. The book Muslims and Jews in France: A History of Conflicts (Mandel, 2014) outlines the history of conflict between Muslims and Jews. Gurfinkiel (2013) asserts that tensions between these two groups' levels entered a new phase that persists today with the establishment of Israel as a Jewish state in 1948 in the wake of World War II \& the Holocaust, resulting in displacement and sociopolitical uncertainty for Palestinians from the territory. Consequently, Jewish support of Israel and Muslim support of Palestinians have influenced the dynamic between members of these two groups globally, including in France.

\section{Recent Anti-Semitic Attacks in France:}

Today, documented incidents of anti-Semitism in Europe in the form of violent attacks are seven times greater than in the 1990s. For example, in 2014 alone, 140 such attacks were reported to the police (Harriss, 2014). Booth and Eglash (2015) reported that the recent trend of growing antiSemitism in Europe has been observed particularly in France, where several attacks have involved Muslim perpetrators subscribing to fundamentalist ideology. According to Gandelman (2007), this disturbing development became more apparent after the September 11, 2001 attacks in the United States by members of the fundamentalist Islamic terrorist organization, Al Qaeda. A comprehensive report by 
the All-Party Parliamentary group against Anti-Semitism (2015) was prepared in an effort to inform the documented attacks of varying degrees of severity that have occurred in Europe and have captured the public's attention.

In 2015, Herzfeld (2015) described in The Washington Post the brutal 2006 killing of Ilan Halimi, a Jewish French man of Moroccan descent by an Algerian with admitted antiSemitic ideology. On March 19, 2012, a Jewish schoolhouse was specifically targeted, resulting in the death of a rabbi and three children (Cody, 2012). In January 2015, the world also took notice of the targeted killing of French Jews at satirical publication Charlie Hebdo and of the gunmen's deliberate choice to continue their rampage at a kosher supermarket, where the predominantly Jewish patrons were held hostage in a standoff with police that concluded in the deaths of the killers (Herzfeld, 2015). Additionally, Smith-Spark and Botelho (2015) of CNN reported on June 26, 2015 that a Muslim extremist beheaded a 54-year old French entrepreneur, Herve Cornora, during a wider terror attack at a transportation company. Gurfinkiel (2013) discussed that these and other similar incidents of late have fueled safety and security concerns among the Jewish French population. French Jews living in Europe are also increasingly concerned about recent evidence of growing anti-Jewish sentiment generally that is manifesting into policy; recent examples include the revocation of previously bestowed legal permission to kosher slaughter and to circumcision by the Council of Europe in Strasbourg, France.

Wainer and Benmeleh (2015) reported that Benjamin Netanyahu, the Prime Minister of Israel, renewed a call for European Jews feeling besieged and targeted to migrate to Israel. While most European Jews have rejected Netanyahu's offer of Aliyah - the invitation to all Jews to migrate to Israel-it highlighted for many a very tangible sense of insecurity, personal and communal (Booth \& Eglash, 2015; Wainer \& Benmeleh, 2015). According to Booth and Eglash (2015), there is justified concern from some European Jews about their continued safety and security as anti-Semitic attacks increase in frequency. According to the Greater Miami Jewish Federation (GMJF. 2015), in the weeks following the January 2015 Charlie Hebdo attacks in France, the Jewish Agency for Israel, an external partner of the GMJF, received more than 1,000 calls per day from concerned French Jews inquiring about the possibility of resettling in Israel, per Prime Minister Netanyahu's invitation.

According to Gurfinkiel (2013), some Jewish families are considering leaving or have already left France, with some making their new homes in the U.S., especially in South Florida. Unfortunately, as the French census does not track religion or ethnicity, it is difficult to arrive at an accurate number or even a reasonable approximation of the number of the individuals of the French Jewry living in France. According to the All-Party Parliamentary Group Against Anti-Semitism (2015), however, while Jewish individuals are estimated at only $1 \%$ of the French population, $40 \%$ of hate crimes in France are directed towards people of Jewish backgrounds. According to Wainer and Benmeleh (2015), as a result of related fear about rising anti-Semitism, there is a growing trend of French-speaking Jews migrating to Israel, Canada, and the United States.

\section{REVIEW OF THE LITERATURE}

An extensive review of the literature from 1933 to the present was conducted on the subject of the individuals of the French Jewry. This review used several databases, including CINAHL, EBSCO, ERIC, Medline, SocINDEX, and other sources including CNN, the American Spectator, Bloomberg and The Washington Post. This search revealed scant information on the problem of how fear and displacement may result in acculturative stress and impact health outcomes of newly migrated Jews. The results were similarly scarce in regards to the recent migration of French Jews to North America, in particular. The search terms included the following: individuals of the French Jewry, culturally tailored nursing care and nursing strategies, and health and wellbeing.

The writers found numerous studies on the assimilation of Jewish immigrants in America in the $20^{\text {th }}$ century. The health status of individuals of the French Jewry in America has not been studied, however, although past studies have discussed in depth the increased emotional stress experienced by immigrant communities of other ethnic groups (Abu-Kaf \& Braun-Lewensohn, 2015). No current study has been undertaken to describe the specific health risk that new immigrants from the French Jewry may face in America because of religious threat. In the book The Psychology of Culture Shock by Ward, Bochner, and Furnham (2001), their germinal works examined the experience of culture shock in diverse populations of immigrants from various countries, as well as varied culture mixes. The authors found an increased incidence of stress displayed as depression in these immigrants, compared with their non-immigrant counterparts. Per the writers' research, no parallel and current study has been added to the literature regarding this potential risk in the recently emigrated population of the French Jewry in the United States, although such studies would inform the health care system on how best to prevent poor outcomes and promote proper health care and wellness in these immigrants.

The following paragraphs will address the phenomenon of acculturation according to Yarova, Krassen Covan, and Fugate-Whitlock (2013). Acculturation entails the act of individuals' immersing themselves into a new culture and leaving behind some traits of their former culture in an effort to adopt a fully integrated new identity. This process may cause a great deal of stress and psychological adjustment for some individuals. As described in Berry's (1997) Immigration, Acculturation, and Adaption, the aim of a formative bimodal acculturation model is to analyze the effects of acculturation. According to Schwartz, Unger, Zamboanga, and Szapocznik, (2010), Berry's model has been criticized for having limitations due to its simplistic nature. Berry's model, nonetheless, will be described as it is widely used and accepted in the literature (Jasinskaja-Lahti, Horenczyk, \& Vedder, 2013). The components of this model include: segregation or separation, assimilation, integration, and marginalization. Segregation or separation describes the act of maintaining an individual's culture and purposefully staying away from and resisting any influence from the host 
culture. By contrast, assimilation is the process of adopting the host culture in full substitution of the previous culture. Integration, which falls somewhere on the spectrum between segregation and assimilation, results from maintaining aspects of the previous culture while incorporating key parts of the new culture. The experience of marginalization is defined as immigrants deciding to exclude themselves from both their culture and the host culture in reaction to discrimination. According to Berry, integration is the best way to achieve social and psychological well-being leading to less anxiety and depressed moods. Berry contends that individuals who feel well do well in society, which leads to them becoming more productive individuals in their communities.

\section{FACTORS AFFECTING ACCULTURATION}

In this section, the differences in acculturation between men and women will be discussed. Miller, Sorokin, and Fogg (2013) examined the difference between the sexes in how they adjusted to displacement. In the study, the researchers tracked multiple factors such as marital fulfillment and communication, depression, social support, isolation, and generativity, which is the process of leaving an individual's customs to the next generation. The researchers found that men generally seemed to adjust better than women in the area of generativity and depressed attitudes with a Pearson correlation of -.16 in males, and -.35 in females. The measuring inventory used the Center for Epidemiological studies -Depression (CES-D was $(F=19.12, d f=10,296, p$ $<$.001). Choi, Kushner, Mill, and Lai (2014) examined The Experience of Korean Immigrant Women Adjusting to Canadian Society and defined culture as a sum of shared meanings expressed in the behaviors, experiences, language, beliefs, and kinships uniting a group of people. The researchers noted that health is integral to that system, as they underlined the importance of health providers having a keen understanding of the cultural background of the diverse individuals in their community, in order to deliver culturally competent care that has a positive impact on health outcomes and improves public health generally. The researchers found negative acculturation as a large part of this issue. According to Vang, Sigouin, Flenon, and Gagnon (2015), women immigrants, in particular, tended to experience more difficulty in integrating into their new culture as they are often responsible for the household, a factor potentially contributing to further isolation.

\section{SIGNIFICANCE OF THE LITERATURE REVIEW}

In a study by Zou and Parry (2012), analyzing ways to promote health education in immigrants to Canada and the United States, the researchers identified obstacles to health education in new immigrants and explored a plan of care for optimal health education using early intervention and cultural sensitivity models tailored to the specific immigrant populations. Among the obstacles to health education identified by the researchers were alignment of the subject's beliefs and customs with the information being taught; proficiency in the language of the host country; the capacity to understand information related to disease prevention and health promotion; and, lastly, social and economic factors such as employment and long-term prospects for successfully integrating in the host country.
To date, the specific populations of young, middle-aged, and older adult French Jews in the United States have not been studied with regard to health care issues. Nonetheless, a cross-sectional study by Abu-Kaf and Braun-Lewensohn (2015) comparing 108 Arab students and 109 Jewish students attending a university in Israel was instructive generally. The subjects for this study were given a Depressive Experiences Questionnaire and other similar surveys looking at selfcriticism, depression, avoidant coping, and social support. In this study, the researchers found less emotional distress among the Jewish students than students of Arab descent. However, this study did not establish that the Jewish students were not at risk; it theorized only that they were at a lower risk of emotional distress than the Arab students. Upon further investigation, the researchers found that self-criticism had a direct relationship among the Jewish students but had only an indirect relationship on depression in the Bedouin Arab student, by means of avoidant coping. Hence, more research is needed to describe the relationship of stress factors on depression in immigrant individuals or those temporarily displaced from their country of origin.

\section{RELIGIOUS OVERVIEW}

Krumrei, Pirutinsky, and Rosmarin (2013) conducted a correlational study with people of Jewish faith in order to explore the connection between spirituality and mental health, in hopes of developing a conceptual model, the purpose of which would be to determine the relationship between depressive symptoms and physical health and religious coping. The researchers sent anonymous Internet surveys to 208 participants, including both men and women living predominantly in the United States and ranging from Orthodox to reform Jewish denominations. While the findings did not lead ultimately to the development of a conceptual model, the researchers linked religious coping with less depressive symptoms and physical health. The authors recommended further longitudinal and experimental studies going forward in order to examine the clinical significance of religion to mental health in the Jewish population (Krumrei et al., 2013).

Gross, Brammli-Greenberg, and Remennick (2001) conducted a correlational study with Jewish immigrants to Israel from the former Soviet Union to examine the perceived health status of women immigrants compared with that of non-immigrant women. The method used questionnaires for a randomized telephone survey of a total of 760 women, aged 22 years of age and older. Although Israel has universal healthcare allowing free access for all residents, the findings revealed increased chronic disease (61\% versus $38 \%$ ), poor health status (7\% versus $4 \%$ ), disability ( $31 \%$ versus $18 \%)$, and depressive moods (52\% versus $38 \%$ ) among the immigrant women as compared to their non-immigrant counterparts (Gross et al., 2001). These findings indicate that women immigrants compared to non-immigrant women had less access to care.

In conclusion, the review of the literature discussed the conflicting interest in France between the Muslims and the French Jewry, the difference in acculturation between men and women, the importance of culturally sensitive care, and the necessity of religious organizations to immigrants. 


\section{Salient Approaches and Concrete Strategies:}

The writers have developed The Bivins \& Hall Model of Culturally Tailored Nursing Strategies for Migrants of the French Jewry (2017) (figure 1). Along with this model, the nursing profession can assist in the challenges and acculturation of individuals of the French Jewry coming to America. The health care implications for this population conceivably may be many, and plans to assist the individuals of the French Jewry to acculturate in America should be developed. In light of the fact that most individuals in this population primarily speak French, without deliberate intervention, it is possible a language barrier may contribute to isolation or delay them from seeking a healthcare provider without deliberate intervention, as theorized by Gross et al. (2001). Since healthcare is socialized in Europe, the writers' working assumption is that this new immigrant population has experience in seeking care but may have issues related to migration stress and general lack of education about the specific options available in the United States.

Gross et al. discovered several barriers to health care utilization among immigrants, including the lack of language fluency that can lead to ineffective communication between the patient and health care provider. Other barriers such as lack of knowledge or general unfamiliarity with the U. S. health care system and differences in health-seeking attitudes may contribute to decreased care and poorer outcomes of immigrants. Since the individuals of the French Jewry are accustomed to socialized medicine, this brings additional barriers to their health-seeking behavior such as reluctance or fear of the health care system. The writers infer from the study by Gross et al. (2001) that enhancement of strategies to connect these individuals to religious organizations such as the GMJF and local synagogues will decrease the stress involved in seeking health care. Therefore, these social organizations will provide opportunities for nurses to get involved in health education and to assist with healthcare access while facilitating the socialization of the French Jewry in communities in the U.S.

In a commentary by Zou and Parry (2012) analyzing ways to promote health education in immigrants, the researchers reviewed germane literature discussing statistics of immigration policy and health education of immigrants in the United States and Canada. They identified several obstacles to health education in new immigrants and explored a plan of care meant to provide optimal health education using cultural sensitivity models tailored to specific immigrant populations. Some of the common factors affecting new immigrants from different backgrounds are their previous level of education, age, culture, religion, and social and economic standing prior to migration. Among the obstacles identified as impeding health education, in particular, among these immigrants were whether their beliefs and customs are aligned with the health information being imparted; their proficiency or lack thereof in the language of the host country; and understanding their health literacy, which is defined by whether they can comprehend information related to disease prevention and promotion. Lastly, social and economic factors such as employment status may impact whether they have transferable skills that would promote their long-term work prospects. Although most of the review was done with Cambodian and Chinese immigrant participants, the results are potentially amenable to generalization and applicable to other immigrant populations as well (Zou \& Parry, 2012).

\section{Culturally Tailored Care:}

Some of the strategies discussed to address these barriers to health education and good outcomes include providing culturally tailored care as discussed in Purnell's model (2014). Purnell's seminal model provides an appropriate framework for understanding the social and cultural impact of relocation in the French Jewish immigrant community. It encompasses 12 domains that are essential to the care of each individual. These domains include: "Overview/Heritage, communication, family roles, workforce issues, biocultural ecology, high risk behavior, nutrition, pregnancy and childbearing activities, death rituals, spirituality, health care practices, and the role of the health care practitioner" (Purnell, 2014, pp. 9-11). These domains will be used in this overview as a guide to maintaining cultural competence in interacting and in providing care to individuals of the French Jewry. The writers assert from Purnell's model that, in assisting this population, nurses and all healthcare providers must be sensitive to the impact of care and to the cultural uniqueness of individuals of the French Jewry they are not seen as culturally distinct.

In establishing initial contact with this population in the context of providing health care information and facilitating their access, the writers would plan to implement services to engage with these new immigrants soon after their arrival to America. For instance, the provider would offer nursing services for new immigrants via the French consulate as well as facilitating referrals to French-speaking physicians and healthcare providers. Nurses, in an attempt to capture the young adults among these new immigrants, should involve themselves at Hillel International (a campus-based religious Jewish organization involved globally) (Falcon \& Blatner, 2013) and form a campus-based nursing clinic to attract new students for workshops focusing on health education, preventive services, and mental health to meet the health needs of the young adult French Jewry. Additionally, nurses must organize health fairs in French schools throughout communities in the U.S. to promote health and wellness in young, middle-aged, and older immigrants. Other contact opportunities might include enabling early intervention by nurses for individuals of the French Jewry involved in Chabad (the largest sect of Orthodox Judaism with community outreach for religious and non-religious Jews) by instituting educational programs such as English as a Second Language (ESL) and health education on non-Chabad days in the local synagogue, with an emphasis on disease prevention, health promotion, and well-being. Nurses may further engage the French consulate of the local city and the Jewish Chamber of Commerce to lend assistance to these individuals to find employment and to involve local French speaking lawyers to assist these individuals with their visa and other immigration-related issues as they secure permanent resident status, as these concerns may have an impact on stress levels.

In accordance with the ANA Nursing's Social Policy Statement (2010), the writers would suggest researching 
individuals of the French Jewry using a phenomenological study to uncover specific customs and beliefs to meet their health needs. Although previously health literate due to the given the reality of socialized medicine in France, this population will need additional health literacy education as a result of possible difficulty with the complexity of the American health system and insurance programs (Todd \& Hoffman-Goetz, 2011). Specific health promotion and disease prevention for young, middle-aged, and older adults should be emphasized. Future studies may elucidate the particular risk factors associated with this population, leading to evidence-based practice that can inform nursing care strategies for improved outcomes.

As the literature suggests, the necessity to support female immigrants is greater than the necessity for the same focus on male immigrants. A lesser number of female immigrants join the workforce, leading to feelings of isolation. Accordingly, the encouragement to join support groups may decrease any feelings of isolation or unfamiliarity. Particularly in Florida, several French social organizations have developed formalized support groups in the community to assist these immigrants with adaptation to the American system. Nurses serving this population may engage with these community groups in a collaborative pursuit of improved healthcare and well-being for these individuals.

Conley, Travers, and Bryant (2013) revealed the advantages of stress management seminars to enhance psychosocial wellbeing and decrease psychological stress in college students. Although in this instance, the study was not particular to immigrants, it is well documented that stress management and support system helps in coping. Also, Locher et al. (2013), in a study at the French College of General Hospital Respiratory Physicians (CPHG), found a two times increase in pulmonary adenocarcinoma cancer irrespective of age, smoking status, and sex in the French population (Locher et al., 2013). Furthermore, in a study by Finch and Vega (2003) Mexican immigrants in California revealed acculturation stressors negatively impacted physical health while social support positively influenced physical health.

As part of their outreach with this community, nurses must provide health information in the form of pamphlets written in French to the French Jewry, in order to facilitate and to improve communication and health literacy. According to Todd and Hoffman-Goetz (2011), in a study examining the relationship between the absorption of information given to immigrants in their native language compared to information relayed in English as a second language, immigrants in Canada exhibited increased health literacy and increased communication in their native language.

\section{CONCLUSION}

In light of the continued migration of individuals of the French Jewry to the United States as a result of rising antiSemitism in France and throughout Europe, the nursing profession must develop concrete approaches and strategies to facilitate health care access for these new immigrants and to promote their health and well-being as part of their successful acculturation. In order to be optimally effective in caring for these new immigrants, nurses must use culturally tailored nursing care to meet their varied needs during this essential time of adjustment. According to ANA Nursing's Social Policy Statement (ANA, 2010), nurses must implement and change health policies based on evidencebased nursing research. As no literature was uncovered addressing health issues in immigrants of the French Jewry in the United States, a specific examination of this population is needed to generate key research that will inform their care and further assist this population to manage the transition to their new lives in the United States.

\section{References}

[1]. Abu-Kaf, S., \& Braun-Lewensohn, O. (2015). Paths to depression among two different cultural contexts: Comparing Bedouin Arab and Jewish students. Journal of Cross-Cultural Psychology, 46(4), 612630. doi:10.1177/0022022115575738

[2]. American Nurses Association. (2010). Nursing's social policy statement (3rd ed.). Washington, DC: American Nurses Association.

[3]. All-Party Parliamentary Group Against AntiSemitism. (2015, February). Report of the All-Party Parliamentary Inquiry into Anti-Semitism. London: All-Party Parliamentary Group Against AntiSemitism. Retrieved from http://www.safecampuscommunities.ac.uk/uploads/fil es/2015/04/antisemitism_report_january_2015.pdf

[4]. Berry, J. W. (1997). Immigration, acculturation, and adaptation. Journal of Applied Psychology. 46(1), 568. Retrieved from http://iaccp.org/sites/default/files/berry_1997.pdf

[5]. Benbassa, E. (1999). The Jews of France: A history from antiquity to the present. Princeton, NJ: Princeton University Press.

[6]. Booth, W., \& Eglash, R. (2015, Jan 15). In Israel, debate over whether French Jews should come or Stay Home? The Washington Post. Retrieved from https://www.washingtonpost.com/world/middle_east/ in-israel-debate-over-whether-french-jews-shouldcome--or-stay-home/2015/01/15/dca63384-9aa311e4-96cc-e858eba91ced_story.html

[7]. Cody, E. (2012, March 19) Rabbi, three children shot dead outside Jewish school in France. The Washington Post. Retrieved from https://www.washingtonpost.com/world/europe/father -two-children-shot-deadoutsidejewish-school-infrance/2012/03/19/gIQAclfUMS story.html

[8]. Conley, C. S., Travers, L. V., \& Bryant, F. B. (2013). Promoting psychosocial adjustment and stress management in first-year college students: The benefits of engagement in a psychosocial wellness seminar. Journal of American College Health, 61(2), 75-86. doi:10.1080/07448481.2012.754757

[9]. Choi, J., Kushner, K.E., Mill, J.,\& Lai, D.W. (2014). The experience of Korean immigrant women adjusting to Canadian society. Journal of Cross 
Cultural Gerontology, 29(3), 277-97, doi:10.1007/s10823-014-9235-8.

[10]. Falcon, T., \& Blatner, D. (2013). Judaism for dummies. (2nd ed.). Hoboken: NJ, John Wiley \& Sons.

[11]. Finch, B. K. \& Vega, W. A. (2003). Acculturative stress, social support, and self-rated health among Latinos in California. Journal of Immigrant Health, 5(3), 109-117.

[12]. Gandelman, J. (2007, March 11). French Jews fleeing into Florida. The Moderate Voice. Retrieved from http://themoderatevoice.com/11430/french-jewsfleeing-into-florida/

[13]. Greater Miami Jewish Federation. (2015). Helping French Jews in a time of crisis. Retrieved from http://jewishmiami.org/news/extra/helping_french_je ws/

[14]. Gross, R., Brammli-Greenberg, S, \& Remennick, L. (2001). Self-rated health status and health care utilization among immigrant and non-immigrant Israeli Jewish women. Women Health, 34(3), 53-69. Retrieved from http://www.ncbi.nlm.nih.gov/pubmed/11708687

[15]. Gurfinkiel, M. (2013, October 13). Exodus: Migration of Jews out of France begins. PJ Media. Retrieved from http://pjmedia.com/blog/exodusmigration-of-jews-out-of-france-begins

[16]. Harriss, J. A. (2014). Racist, moi? American Spectator, 47(7), 46-47. Retrieved from http://spectator.org/articles/61019/racist-moi

[17]. Herzfeld, S. (2015, January 13). The U.S. should open its doors to imperiled European Jews. The Washington Post. Retrieved from http://www.washingtonpost.com/posteverything/wp/2 015/01/13/the-u-s-should-open-its-doors-to-europeanjews/

[18]. Jasinskaja-Lahti, I., Horenczyk, G., \& Vedder, P. (2013). Migration and integration: Some psychological perspectives on mutual acculturation. Zeitschrift Fur Psychologie, 221(4), 203-204. doi:10.1027/2151-2604/a0001549

[19]. Krumrei, E., Pirutinsky, S., \& Rosmarin, D. (2013). Jewish spirituality, depression, and health: An empirical test of a conceptual framework. International Journal of Behavioral Medicine, 20(3), 327-336. doi:10.1007/s12529-0129248-z

[20]. Locher, C., Didier, D, Coetmeur, D, Goupil, F., Moliner, O., Collon, T., ... Grivaux, M. (2013). Major changes in lung cancer over the last 10 years in France: The KBP-CPHG Studies. Lung Cancer, 81(1), 32-38.

[21]. Mandel, M. S. (2014). Muslims and Jews in France: History of a conflict. Princeton, NJ: University Press.

[22]. Miller, A.M., Sorokin, O., \& Fogg, L. (2013). Individual, family, social, and cultural predictors of depressed mood in Former Soviet immigrant couples. Research in Nursing \& Allied Health, 36(3), 271-283. doi:10.1002/nur.21535.

[23]. Purnell, L.D. (2014). Guide to culturally competent health care (3rd ed.). Philadelphia. PA: F.A. Davis Company.

[24]. Smith-Spark, L., \& Botelho, G. (2015, June). Suspect detained after beheading, explosion in France. CNN.

Retrieved from

http://www.cnn.com/2015/06/26/europe/france$\underline{\text { attack/ }}$

[25]. Schwartz, S.J., Unger, J.B, Zamboanga, B.L., \& Szapocznik, J. (2010). Rethinking the concept of acculturation: Implications for theory and research. American Psychologist, 65(4), 237-251. doi:10.1037/a0019330

[26]. Todd, L., \& Hoffman-Goetz, L. (2011). Predicting health literacy Among English-as-a-second Language older Chinese immigrant women to Canada: Comprehension of colon cancer prevention information. Journal of Cancer Education, 26(2), 326332. doi:10.1007/s13187-010-0162-2

[27]. Vang, Z., Sigouin, J., Flenon, A., \& Gagnon, A. (2015). The healthy immigrant effect in Canada: A systematic review. Scholarship at Western, 3(1), 1-41 Retrieved from http://ir.lib.uwo.ca/cgi/viewcontent.cgi? article=1012 \&context $=$ pclc

[28]. Wainer, D., \& Benmeleh, Y. (2015, January 22). Israel gains with influx of French Jewish entrepreneurs. Bloomberg. Retrieved from http://www.bloomberg.com/news/articles/2015-0122/israel-gains-as-france-loses-entrepreneurs-amongpersecuted-jews

[29]. Ward, C., Bochner, S., \& Furnham, A. (2001). The psychology of culture shock (2nd ed.). Abingdon: UK. Routledge: Taylor \& Francis Group.

[30]. Welch, S. (2014). American opinion toward Jews during the Nazi era: Results from quota sample polling during the 1930s and 1940s. Social Science Quarterly, 95(3), 615-635. doi: 10.1111/ssqu.12084

[31]. World Health Organization. (2017). Constitution of WHO principles. Retrieved from http://www.who.int/about/mission/en/

[32]. Yarova, L. A., Krassen Covan, E., \& FugateWhitlock, E. (2013). Effect of acculturation and health beliefs on utilization of health care services by elderly women who immigrated to the USA from the Former Soviet Union. Health Care for Women International, 34(12), 1097-1115. doi:10.1080/07399332.2013.807259

[33]. Zou, P., \& Parry, M. (2012). Strategies for health education in North American immigrant populations. International Nursing Review, 59(4), 482-488. doi:10.1111/j.1466 7657.2012.01021.x 


\section{Migrant Integration into Community Culturally Tailored Nursing Strategies}

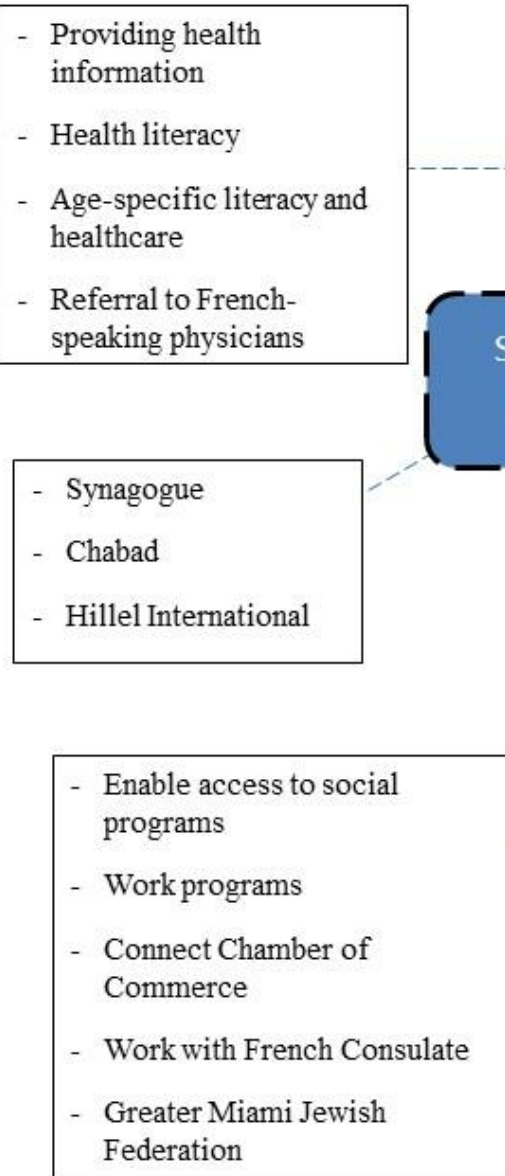

- Providing health mation

Age-specific literacy and thcare

Referral to Frenchspeaking physicians Federation

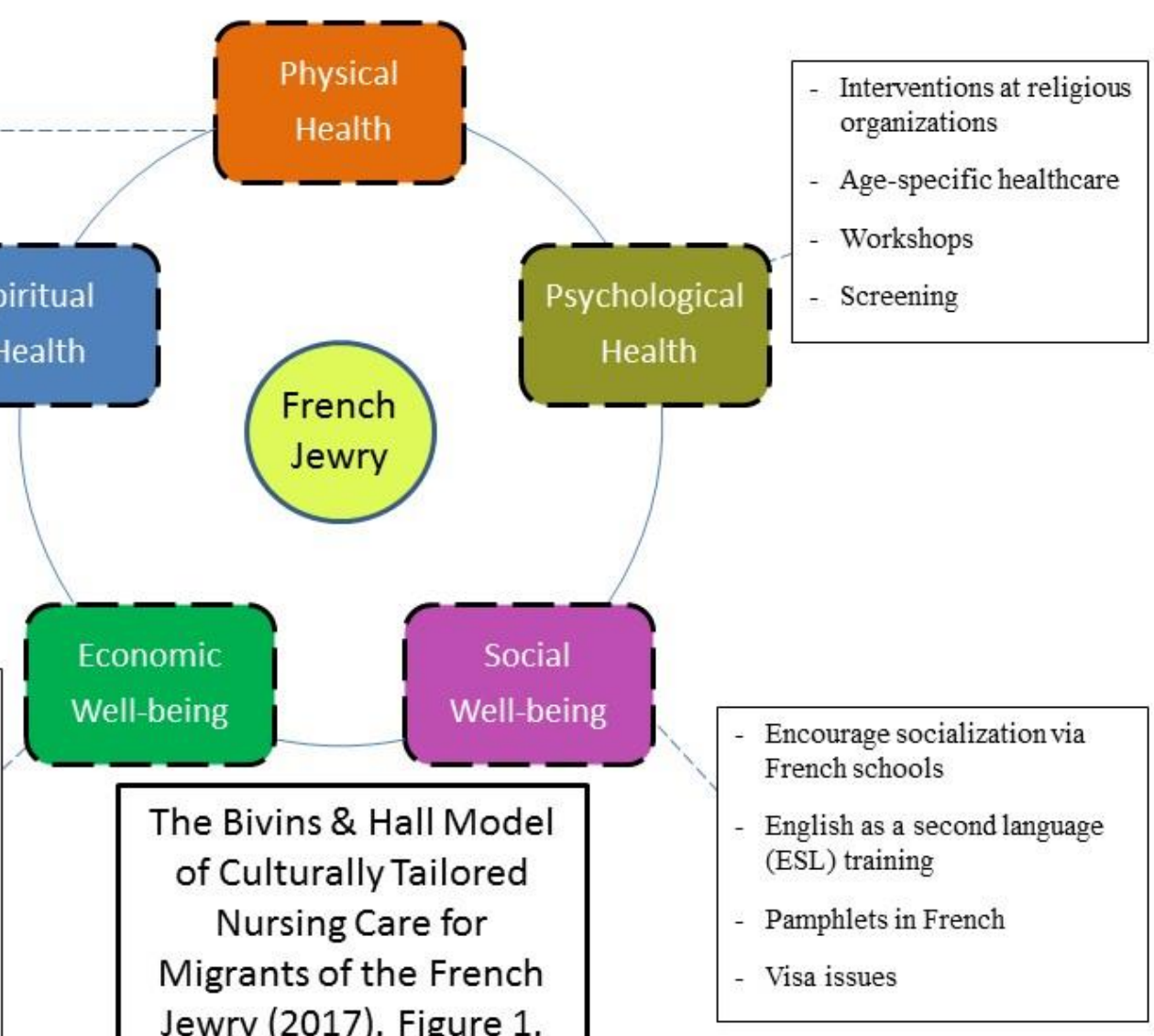

